Article

\title{
In Vitro Corrosion Assessment of Additively Manufactured Porous NiTi Structures for Bone Fixation Applications
}

\author{
Hamdy Ibrahim ${ }^{(0)}$, AhmadReza Jahadakbar, Amir Dehghan, Narges Shayesteh Moghaddam, \\ Amirhesam Amerinatanzi and Mohammad Elahinia * (D) \\ Dynamic and Smart Systems Laboratory, Mechanical Industrial and Manufacturing Engineering Department, \\ The University of Toledo, Toledo, $\mathrm{OH}$ 43606, USA; hamdy.m.elsayed@gmail.com (H.I.); \\ ar.jahadakbar@gmail.com (A.J.); amirdehghan.g@gmail.com (A.D.); shayesteh.narges@gmail.com (N.S.M.); \\ amirameri83@gmail.com (A.A.) \\ * Correspondence: mohammad.elahinia@utoledo.edu; Tel.: +1-419-530-8224
}

Received: 14 January 2018; Accepted: 6 March 2018; Published: 8 March 2018

\begin{abstract}
NiTi alloys possess distinct functional properties (i.e., shape memory effect and superelasticity) and biocompatibility, making them appealing for bone fixation applications. Additive manufacturing offers an alternative method for fabricating NiTi parts, which are known to be very difficult to machine using conventional manufacturing methods. However, poor surface quality, and the presence of impurities and defects, are some of the major concerns associated with NiTi structures manufactured using additive manufacturing. The aim of this study is to assess the in vitro corrosion properties of additively manufactured NiTi structures. NiTi samples (bulk and porous) were produced using selective laser melting (SLM), and their electrochemical corrosion characteristics and $\mathrm{Ni}$ ion release levels were measured and compared with conventionally fabricated NiTi parts. The additively manufactured NiTi structures were found to have electrochemical corrosion characteristics similar to those found for the conventionally fabricated NiTi alloy samples. The highest $\mathrm{Ni}$ ion release level was found in the case of $50 \%$ porous structures, which can be attributed to their significantly higher exposed surface area. However, the Ni ion release levels reported in this work for all the fabricated structures remain within the range of most of values for conventionally fabricated NiTi alloys reported in the literature. The results of this study suggest that the proposed SLM fabrication process does not result in a significant deterioration in the corrosion resistance of NiTi parts, making them suitable for bone fixation applications.
\end{abstract}

Keywords: Nitinol alloys; additive manufacturing; selective laser melting; in vitro corrosion; porous structures; bone implants

\section{Introduction}

Recently, Nickel-titanium (NiTi) alloys, also known as Nitinol, have become attractive for various applications due to their unique characteristics, such as their shape memory behavior and superelasticity, which allows them to recover from large strains as high as $8 \%$ [1-4]. In addition, NiTi alloys are more biocompatible when implanted inside the human body, and have a more desirable strength and modulus of elasticity compared to the metallic alloys conventionally used (e.g., Ti-6Al-4V) [5-8]. The advantageous properties of NiTi alloys make them appealing for different biomedical load-bearing applications, such as staples, clamps, orthodontic wires and bone implants. The high biocompatibility of NiTi alloys is due to their high corrosion resistance, which can be attributed to the fast formation of protective layers on the surface, especially when exposed to Cl-containing environments (e.g., physiological environment). These protective layers mainly consist 
of $\mathrm{TiO}, \mathrm{TiO}_{2}$ and $\mathrm{Ti}_{2} \mathrm{O}_{3}$, which are considerably more stable than the NiTi alloy [8-11]. It has been reported that the composition of the protective layers on the surface of NiTi parts depends mainly on the surface characteristics and the composition of the testing solution [12-14]. For instance, the effects of intraoral aging on the surface properties of esthetic and conventional NiTi was studied by Rongo et al. [15]. They found that, even for coated NiTi wires, the surface properties-including the surface roughness-could be altered during and after their clinical use. In addition, the immersion of NiTi alloys in Hank's solution mostly forms $\mathrm{TiO}_{2}, \mathrm{Ca}_{3}\left(\mathrm{PO}_{4}\right)_{2}$ and small traces of $\mathrm{Ni}(\mathrm{OH})_{2}$ as the products of the corrosion process $[11,16]$.

Despite the protection from corrosion provided by the formed layers on the surface of NiTi parts, it has been reported in several studies that NiTi parts could release nickel (Ni) ions when exposed to a physiological environment for long implantation durations [17]. Ni ions are known to be harmful to the surrounding living tissues and to cause allergic reaction and genotoxicity in the human body $[11,18,19]$. Ryhanen et al. [20] performed a comparative in vitro cell culture study to measure $\mathrm{Ni}$ ions released from polished NiTi and electro-polished 316 L stainless steel in a cell culture media. In both cases, NiTi samples showed higher $\mathrm{Ni}$ ion levels for the first day, with a rapid decrease over the next eight consecutive days until the $\mathrm{Ni}$ ion release levels of the 316L stainless steel samples were reached. They found that, despite the higher $\mathrm{Ni}$ ion release in non-passivated NiTi samples, the ion concentration value was not high enough to kill the adjacent cells due to toxicity. In a similar set of studies conducted by Wever et al. [16], the Ni ion release of passivated NiTi samples was investigated and compared with 316L stainless steel samples. They found the same results as Ryhanen et al. [20] and reported a Ni ion release rate of $14.5 \times 10^{-7} \mu \mathrm{g} \cdot\left(\mathrm{cm}^{2} \cdot \mathrm{s}\right)^{-1}$. Likewise, El Medawar et al. [21] investigated the $\mathrm{Ni}$ ion release of NiTi samples exposed to different sets of cells and reported that the amount of released $\mathrm{Ni}$ ions were $0.098 \pm 0.006 \mathrm{ppm}$ and $0.104 \pm 0.007 \mathrm{ppm}$ after 3 and 6 days, respectively. The control medium had a constant $\mathrm{Ni}$ ion release of $0.01 \mathrm{ppm}$ in the investigation period. In another study, Bernard et al. [22] reported a maximum of $268 \pm 11 \mathrm{ppb}$ of Ni ion release in NiTi samples.

NiTi alloys are difficult to process using conventional methods and procedures (e.g., machining). This can be attributed to many reasons, such as the stress-induced martensitic transformation, work hardening, spring-back effects, and burr formation of NiTi alloys [5]. These are the main reasons that the vast majority of practical NiTi devices developed so far have simple and limited geometries, such as wires, tubes, sheets and thin rods. In addition, NiTi is very sensitive to impurity pick up, which makes high-temperature processing challenging $[5,23]$. These impurities result in the formation of Ti-rich brittle phases, which affect the functional and structural properties of the material. Recently, Additive Manufacturing (AM) methods have been developed for the fabrication of metallic parts, including NiTi $[24,25]$. This near-net-shaping technology has been able to overcome the manufacturing limitations and has enabled the fabrication of complex geometries, such as scaffolds and porous structures $[5,24,26]$. In AM methods, the final part is fabricated directly from a Computer Aided Design (CAD) file using layer-by-layer fabrication. This powerful method of fabrication has enabled researchers to design and introduce realistic NiTi implants, actuators, and medical devices with complex geometries that benefit from superelastic and shape memory effects. Several studies have introduced patient-specific, stiffness-matched NiTi bone fixation plates that can be fabricated using additive manufacturing $[27,28]$. The stiffness matching offers significantly better outcomes for patients and has been achieved by imposing specific levels and types of porosity on the NiTi parts. The use of additive manufacturing in the biomedical field is not limited to the fabrication of metallic parts, but it enables the fabrication of complex shapes for a wide range of materials, including polymers and polymer-based composites [29-31]. For example, Martorelli et al. [32] used additive manufacturing to fabricate customized polymer-based composite mandibles that simulate the mechanical behavior of a human mandible.

The use of AM fabrication techniques and the introduction of porosity to the NiTi parts add other factors that may affect the corrosion characteristics of 3D-printed NiTi alloys and hence the release of the $\mathrm{Ni}$ ions in the physiological environment. After an extensive review of the literature, 
it was found that the corrosion behavior of the additively manufactured NiTi parts has not yet been evaluated. This study focuses on the in vitro evaluation of the corrosion behavior of additively manufactured NiTi parts, fabricated using a selective laser melting (SLM) process, represented in their electrochemical corrosion characteristics and Ni ion release levels. The chosen SLM process provides more freedom to change the level of introduced porosity, pore morphology and material composition of the fabricated NiTi parts needed for bone implant applications. In addition, this work is the first to assess the corrosion and ion release behavior of the porous NiTi parts compared to 1bulk 3D-printed and conventionally fabricated NiTi parts.

\section{Materials and Methods}

\subsection{Design and Fabrication of the Samples}

Selective Laser Melting (SLM) was used to fabricate the samples. $\mathrm{Ni}_{50.8} \mathrm{Ti}_{49.2}$ (at \%). Ingots from NiTi Devices and Components, Inc. (Fremont, CA, USA), were provided as the raw material for the SLM process. The ingots were atomized to powder using the Electrode Induction-melting Gas Atomization (EIGA) technique (by TLS Technique GmbH (Bitterfeld, Germany)). Finally, the prepared powder in 25-75 $\mu \mathrm{m}$ particle fractions was used as the input material for the Phenix PXM SLM machine (3D Systems, Valencia, CA, USA). The utilized SLM machine was equipped with a $300 \mathrm{~W}$ Ytterbium fiber laser with a beam quality of $M^{2}<1.2$. The beam profile of the machine was Gaussian $\left(\mathrm{TEM}_{00}\right)$, and the beam diameter was about $80 \mu \mathrm{m}$. Table 1 summarizes the process parameters used for fabrication of the parts. More details on the fabrication of the samples using the Phenix machine can be found our previous studies $[27,28]$.

Table 1. Process parameters used in Selective Laser Melting (SLM) manufacturing of NiTi parts.

\begin{tabular}{|c|c|c|c|c|}
\hline Effective Laser Power (W) & Layer Thickness ( $\mu \mathrm{m})$ & Scanning Velocity $(\mathrm{m} / \mathrm{s})$ & Hatch Distance $(\mu \mathrm{m})$ & Energy Input $\left(\mathrm{J} / \mathrm{mm}^{3}\right)$ \\
\hline 250 & 30 & 1.25 & 120 & 55.5 \\
\hline
\end{tabular}

In order to study the corrosion response of the additively manufactured NiTi parts, bulk and porous cubic samples with dimensions of $9 \mathrm{~mm} \times 9 \mathrm{~mm} \times 9 \mathrm{~mm}$ were designed and fabricated. The porous samples were designed by imposing porosity at different levels (15-50\%), as shown in Figures 1 and 2. Samples for electrochemical corrosion characterization were fabricated with the same dimensions, with an additional hook connected at the top surface of the cubes for better electrical connectivity during the test. The fabricated samples were then separated from the base by using an EDM cutting machine.

In vitro corrosion assessment of the additively manufactured (AM) NiTi parts (bulk and porous) was performed, and it was compared to the conventionally fabricated NiTi alloy (same atomic composition) using immersion ( $\mathrm{Ni}$ ion release) and electrochemical corrosion tests. A simulated body fluid (SBF) medium, prepared according to Oyane et al. [33], was used for the in vitro tests, see Table 2. The tested samples were polished using a sand blaster, and the samples for electrochemical corrosion characterization were further polished using SiC papers from 180 to 1500 grit. All the tested samples (immersion and electrochemical tests) were then cleaned by water and ultrasonically cleaned by ethanol before each test. 
Table 2. Composition of $1000 \mathrm{~mL}$ solution of a modified SBF [33].

\begin{tabular}{cc}
\hline Reagent & Amount \\
\hline $\mathrm{NaCl}$ & $5.403 \mathrm{~g}$ \\
$\mathrm{NaHCO}_{3}$ & $0.504 \mathrm{~g}$ \\
$\mathrm{Na}_{2} \mathrm{CO}_{3}$ & $0.426 \mathrm{~g}$ \\
$\mathrm{KCl}$ & $0.225 \mathrm{~g}$ \\
$\mathrm{~K}_{2} \mathrm{HPO}_{4} \cdot 3 \mathrm{H}_{2} \mathrm{O}$ & $0.23 \mathrm{~g}$ \\
$\mathrm{MgCl}_{2} \cdot 6 \mathrm{H}_{2} \mathrm{O}$ & $0.311 \mathrm{~g}$ \\
$0.2 \mathrm{~mol} \mathrm{~L}^{-1} \mathrm{NaOH}$ & $100 \mathrm{~mL}$ \\
$\mathrm{HEPES}_{\mathrm{CaCl}}$ & $17.892 \mathrm{~g}$ \\
$\mathrm{Na}_{2} \mathrm{SO}_{4}$ & $0.293 \mathrm{~g}$ \\
$1 \mathrm{~mol} \mathrm{~L}^{-1} \mathrm{NaOH}$ & $0.072 \mathrm{~g}$ \\
\hline
\end{tabular}
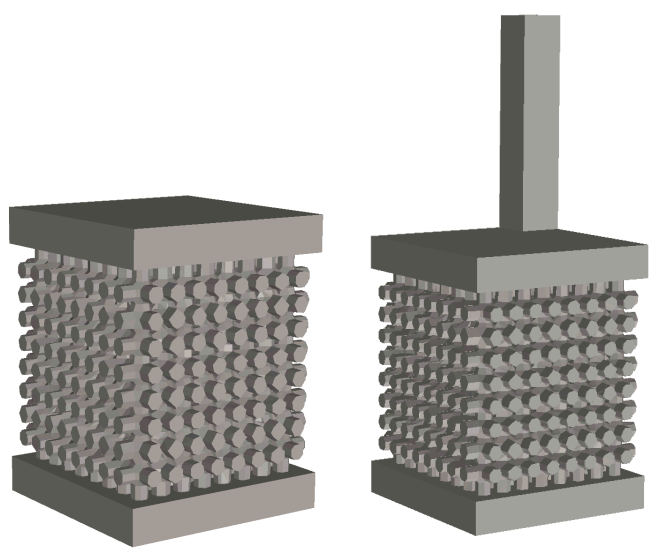

Figure 1. CAD files of the immersion and electrochemical samples.

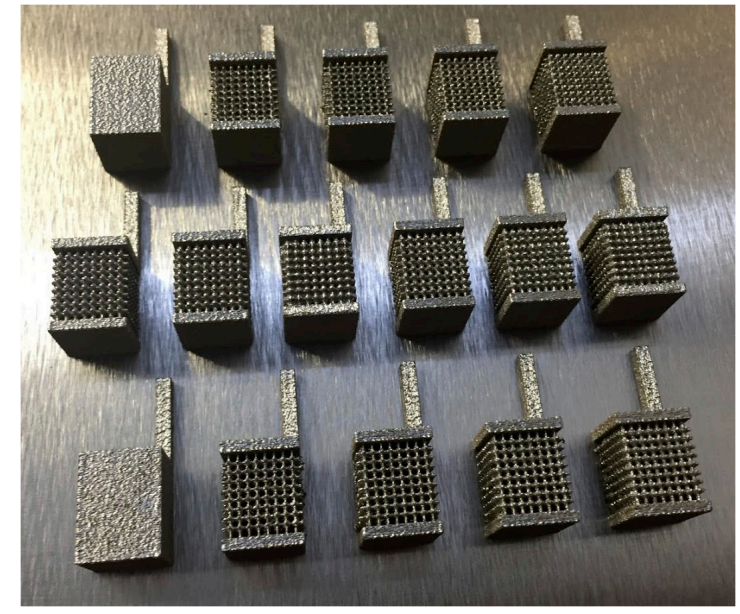

Figure 2. Fabricated samples for electrochemical tests.

\subsection{Electrochemical Corrosion Test}

Samples were molded into epoxy resin with a determined area exposed. In the cases of conventionally fabricated and AM samples, the same exposed area of $0.5 \mathrm{~cm}^{2}$ was chosen for better comparison. In the case of the bulk and porous structures, the whole side surfaces of the part were exposed, and only the top surfaces were covered with epoxy, see Figure 3. In this way, a better comparison between the electrochemical corrosion characteristics of bulk and porous NiTi devices could be determined. 


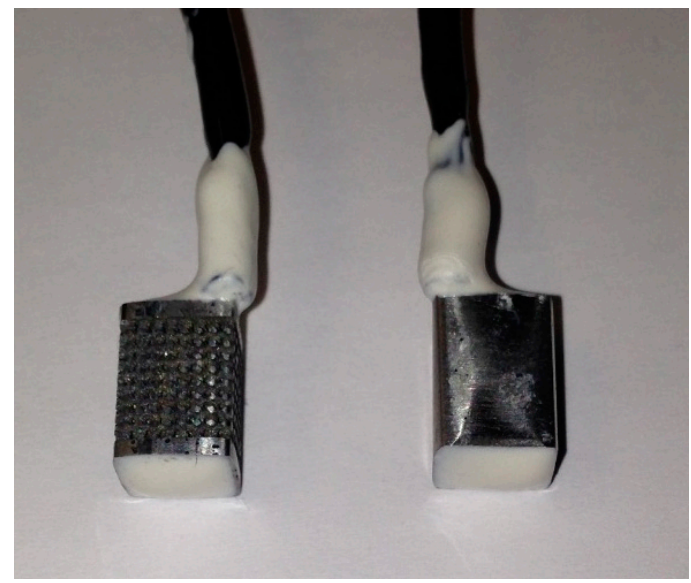

Figure 3. The epoxy molding of the bulk and porous samples and exposed surfaces after the electrochemical corrosion test in SBF.

A Gamry (Gamry, Centennial, CO, USA) Instruments Potentiostat was used to perform the potentiodynamic polarization (PDP) test in the SBF at $\mathrm{pH} 7.4,37 \pm 1^{\circ} \mathrm{C}$ and a constant scan rate of $1 \mathrm{mV} / \mathrm{s}$ from -250 to $+1000 \mathrm{mV}$ (versus ref. voltage) with respect to the OCP value. A standard three-electrode system with silver chloride $(\mathrm{Ag} / \mathrm{AgCl})$ as the reference electrode, graphite rod as the counter electrode, and the sample as the working electrode, see Figure 4, was used. The potential values obtained from the silver chloride reference electrode were properly converted to the standard calomel electrode (SCE) potentials for better comparison with the literature. Open circuit potential (OCP) of the samples was measured for durations of $60 \mathrm{~min}$ to attain a stable state prior the experiment. Graphical Tafel analysis was used to obtain the corrosion characteristics such as current densities and corrosion potentials.

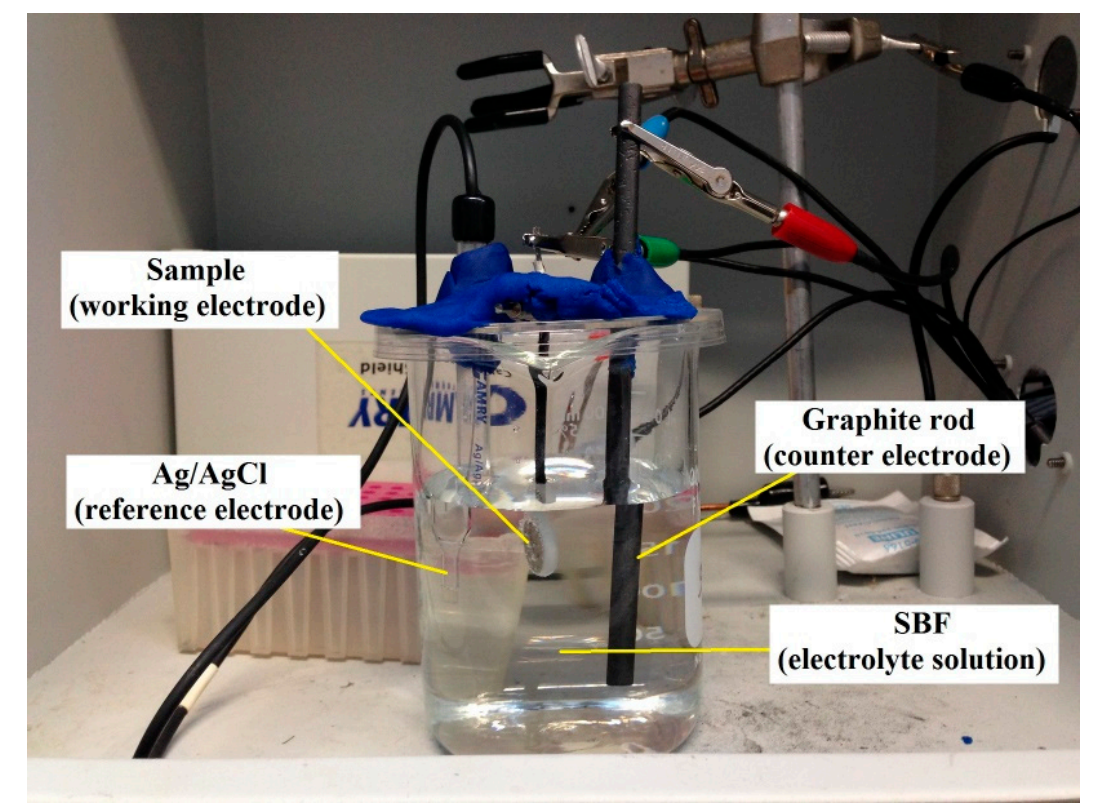

Figure 4. The electrochemical cell unit used for determining the electrochemical characteristics of the prepared samples. 


\subsection{Surface Morphology}

The surface morphology of the NiTi parts after the in vitro potentiodynamic polarization test was investigated using scanning electron microscopy (SEM). A Hitachi (Tokyo, Japan) S-4800 scanning electron microscope equipped with energy dispersive spectroscopy (EDS) analysis was used for this purpose. EDS analysis was used to conduct an elemental analysis on the surface's corrosion products.

\subsection{X-ray Diffraction (XRD)}

The composition of the surface of the samples before and after the electrochemical corrosion test was investigated using a Rigaku Ultima III X-ray Diffractometer (Rigaku, Tokyo, Japan) with Small Angle X-ray Scattering (SAXS), provided by Rigaku, Tokyo, Japan. XRD with parallel beam (PB) mode was used, and the analysis was acquired for $2 \theta$ from $20^{\circ}$ to $90^{\circ}$ with a step size of 0.05 at $35 \mathrm{~mA}$ and $40 \mathrm{kV}$ using $\mathrm{Cu} \mathrm{K} \alpha$ radiation.

\subsection{Ni Ion Release (Immersion Test)}

The immersion test was conducted by submerging the sand-blast polished and ethanol-degreased samples in polypropylene tubes filled with $20 \mathrm{~mL} \mathrm{SBF}$ solution at $\mathrm{pH} 7.4$ and $37^{\circ} \mathrm{C}$. The temperature was maintained at $37{ }^{\circ} \mathrm{C}$ by placing the tubes in a rotary incubator throughout the period of the test ( 3 days). The continuous rotation of the tubes (at $20 \mathrm{rpm}$ ) during the immersion test was used to accelerate the corrosion process and shorten the immersion test duration. In this study, the $\mathrm{pH}$ of all the tested samples was recorded daily and the amount of $\mathrm{Ni}$ ion released in $\mathrm{ppb}$ after 3 days of exposure was measured using Inductively Coupled Plasma Atomic Emission Spectroscopy (ICP-AES). For each tested sample, $1 \mathrm{~mL}$ of the SBF medium after 3 days was diluted with deionized water at a ratio of 1:10 in order to produce an adequate sample size and ion concentrations for spectrometry. Calculations were performed according to these dilutions to determine the actual Ni ion release after immersion. The samples were analyzed using the $X$-series 2 from Thermo Scientific. For quantitative analysis, certified ICP-MS standards from Inorganic Ventures were prepared at $2 \% \mathrm{HNO}_{3}$. Correlation coefficients for calibration curves were above 0.999 . The ionic concentrations ( $\mathrm{mmol} / \mathrm{L}$ ) of the SBF used in the present study were determined by Hansen et al. [34] and were as follows: $142.0 \mathrm{Na}^{+}, 5.0 \mathrm{~K}^{+}$, $1.5 \mathrm{Mg}^{2+}, 2.5 \mathrm{Ca}^{2+}, 147.8 \mathrm{Cl}^{-}, 4.2 \mathrm{HCO}_{3}{ }^{-}, 1.0 \mathrm{HPO}_{4}{ }^{2-}$ and $0.5 \mathrm{SO}_{4}{ }^{2-}$.

\section{Results and Discussion}

\subsection{Electrochemical Corrosion Test}

In vitro corrosion behavior of NiTi plays a significant role in determining the functionality of biomedical devices in the human body. Figure 5 shows the Tafel curves of the conventionally fabricated NiTi alloy and the additively manufactured NiTi alloy. The additively manufactured NiTi alloy shows corrosion characteristics $\left(20 \pm 2.1 \mu \mathrm{A} / \mathrm{cm}^{2}\right.$ current density and $-0.394 \pm 0.01 \mathrm{~V}$ corrosion potential) comparable to those for the biocompatible conventionally fabricated NiTi alloy $\left(12 \pm 3.8 \mu \mathrm{A} / \mathrm{cm}^{2}\right.$ current density and $-0.4155 \pm 0.008 \mathrm{~V}$ corrosion potential). The similar corrosion characteristics of the additively manufactured and conventionally fabricated NiTi samples imply homogenization in the microstructure and the absence of apparent defects for the AM NiTi parts that could deteriorate the corrosion properties. The Tafel curves also show a slightly higher corrosion current density for the AM NiTi alloy compared with the conventionally fabricated one. However, such a small difference is within the acceptable range and does not have a significant effect on the corrosion behavior of the additively manufactured NiTi samples. This indicates that the additive manufacturing process does not result in a significant change in the electrochemical corrosion characteristics of NiTi alloys.

Figure 6 shows the Tafel curves of two structures with the same volume produced by additive manufacturing: bulk structure and porous structure (35\% porosity level). As expected, the higher surface area and the presence of many edges in the case of the porous structures resulted in a higher corrosion current. For instance, the corrosion current increased from about $200 \mathrm{nA}$ for a bulk structure 
to be $950 \mathrm{nA}$ for a $35 \%$ porous structure. This increase in the corrosion currents is expected to result in more corrosion byproducts and a higher amount of $\mathrm{Ni}$ ion released in vivo.

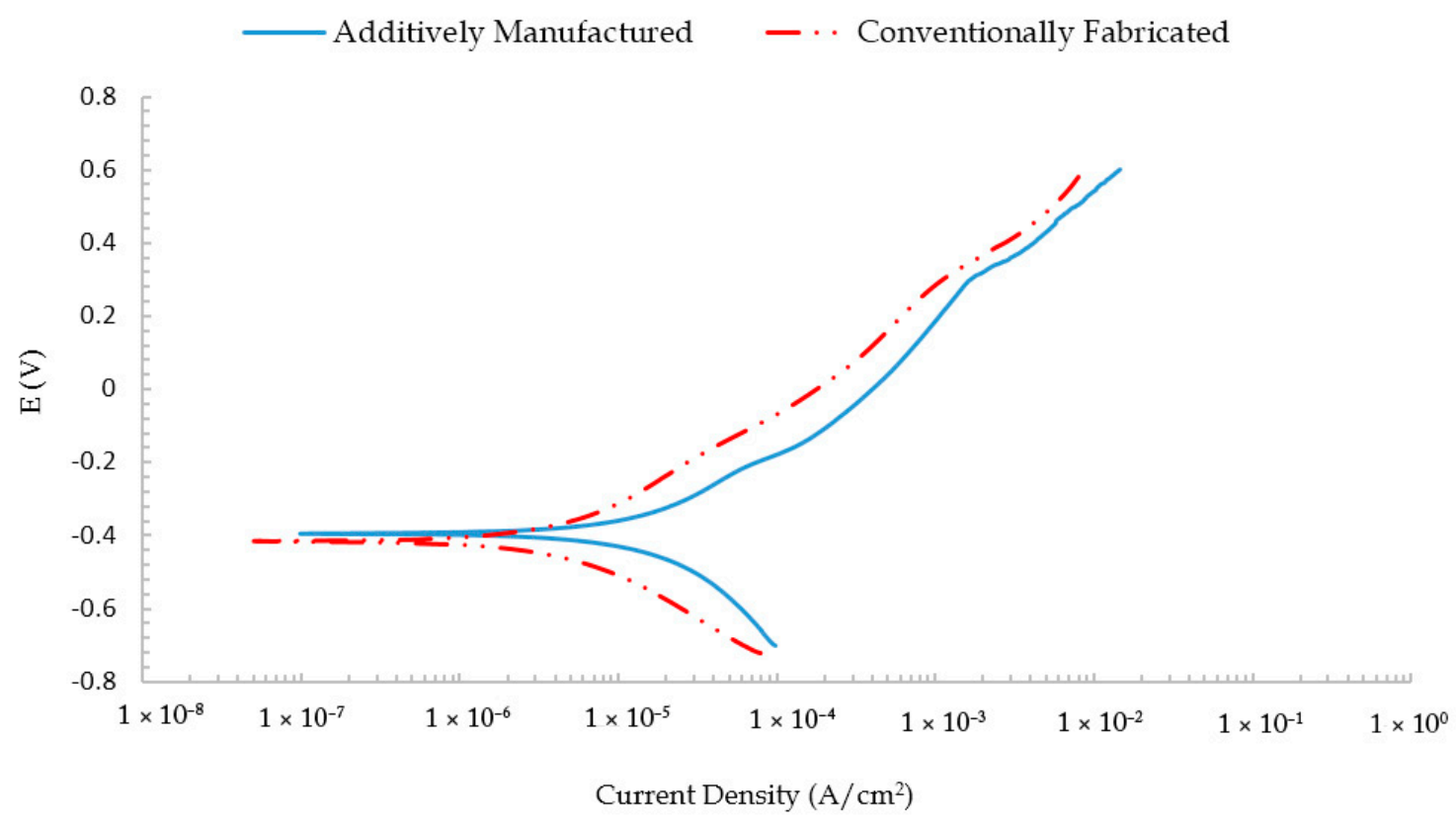

Figure 5. The potentiodynamic polarization curves of the conventionally fabricated and additively manufactured NiTi alloy samples.

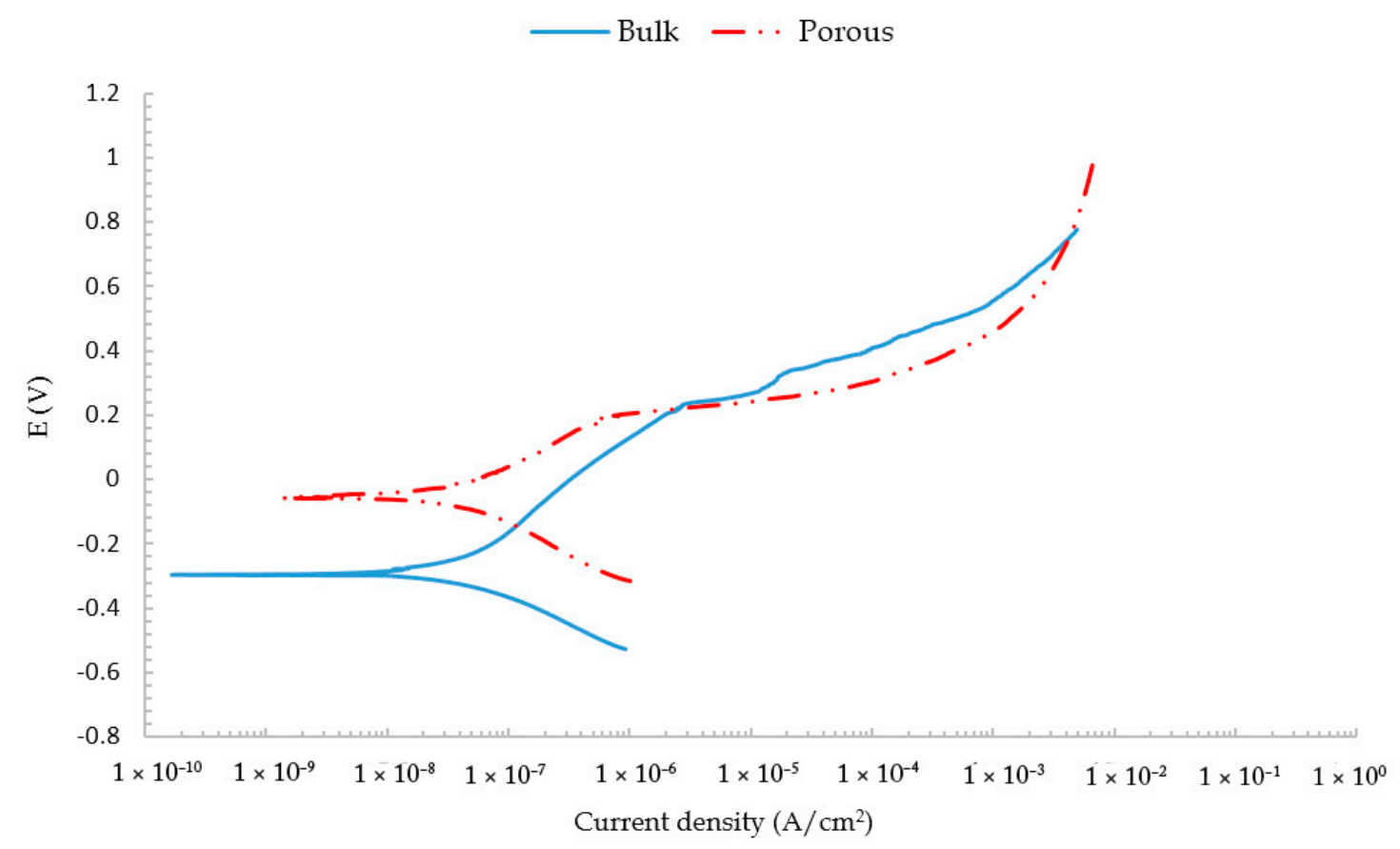

Figure 6. The potentiodynamic polarization curves of the AM NiTi alloys with two different structures; bulk and $30 \%$ porous structure.

\subsection{Surface Morphology}

SEM investigation and EDS analysis were used to study the morphology and elemental composition of corroded surfaces for the AM NiTi parts after the in vitro potentiodynamic 
polarization test, as seen in Figure 7. The corroded surfaces showed several pits with corrosion product agglomerations on the surface. This assures the occurrence of pitting corrosion for the tested samples. The pits observed on the surface of the AM NiTi parts were circular, with a diameter varying between 50 and $250 \mu \mathrm{m}$. The EDS elemental analysis showed that the agglomerated corrosion products on the surface of the samples (point 1), concentrated inside and around the pits, consisted mainly of sodium, phosphorous and sulfur-based compounds alongside oxygen, $\mathrm{Ti}$ and Ni. However, the elemental analysis away from the pits (point 2) showed no traces of sodium, phosphorus, or sulfur. The presence of oxygen on the surface implies the existence of oxide layers after the corrosion test.
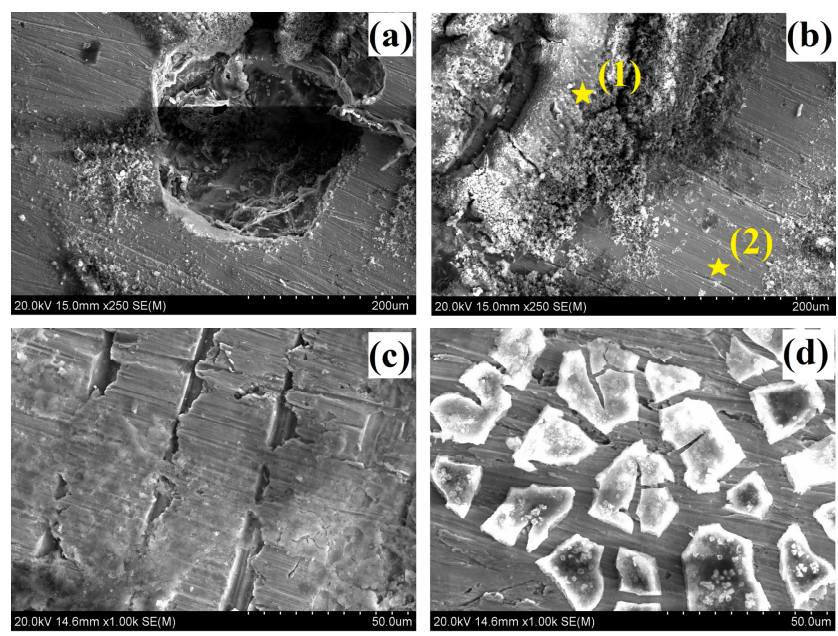

\begin{tabular}{cccccccccc}
\hline \multirow{2}{*}{ Point } & \multicolumn{8}{c}{ Element Wt.\% } \\
\cline { 2 - 10 } & O & Na & P & S & Cl & K & Ca & Ti & Ni \\
\hline 1 & 30.4 & 4.96 & 1.65 & 10.39 & 7.85 & 1.53 & 1.53 & 32.0 & 8.69 \\
2 & 10.25 & 0.0 & 0.0 & 0.0 & 0.0 & 0.0 & 0.0 & 41.56 & 48.19
\end{tabular}

Figure 7. SEM investigation and EDS point spectrum analysis of the corroded surface after the potentiodynamic polarization test in $\mathrm{SBF}$ at $7.4 \mathrm{pH}$ and $37^{\circ} \mathrm{C},(\mathbf{a}, \mathbf{b})$ show the pits with corrosion product agglomerations at $250 \times$ magnification; $(\mathbf{c}, \mathbf{d})$ show the corroded surface at $1000 \times$ magnification.

\subsection{X-ray Diffraction (XRD)}

XRD tests were conducted to determine the compounds available on the surface of the samples before and after the corrosion process. Figure 8 represents the overlapped graphs of XRD of the NiTi samples before and after corrosion. As can be seen, in the graph of additively manufactured NiTi sample, the peaks of NiTi appeared in locations around 28,43, 61 and 76 degrees, with the second peak being the highest in intensity. However, in the XRD graph of the corroded sample, the NiTi peaks were smaller in intensity, while new phases of $\mathrm{HA}$ and $\mathrm{TiO}_{2}$ emerged. These peaks belong to the corrosion products deposited on the surface of the sample after exposure to the corrosive environment. Moreover, the results of XRD were in a complete agreement with the EDS elemental analysis. Such biocompatible products, in addition to their role in bone growth stimulation, may also act as corrosion barriers that decelerate corrosion. 


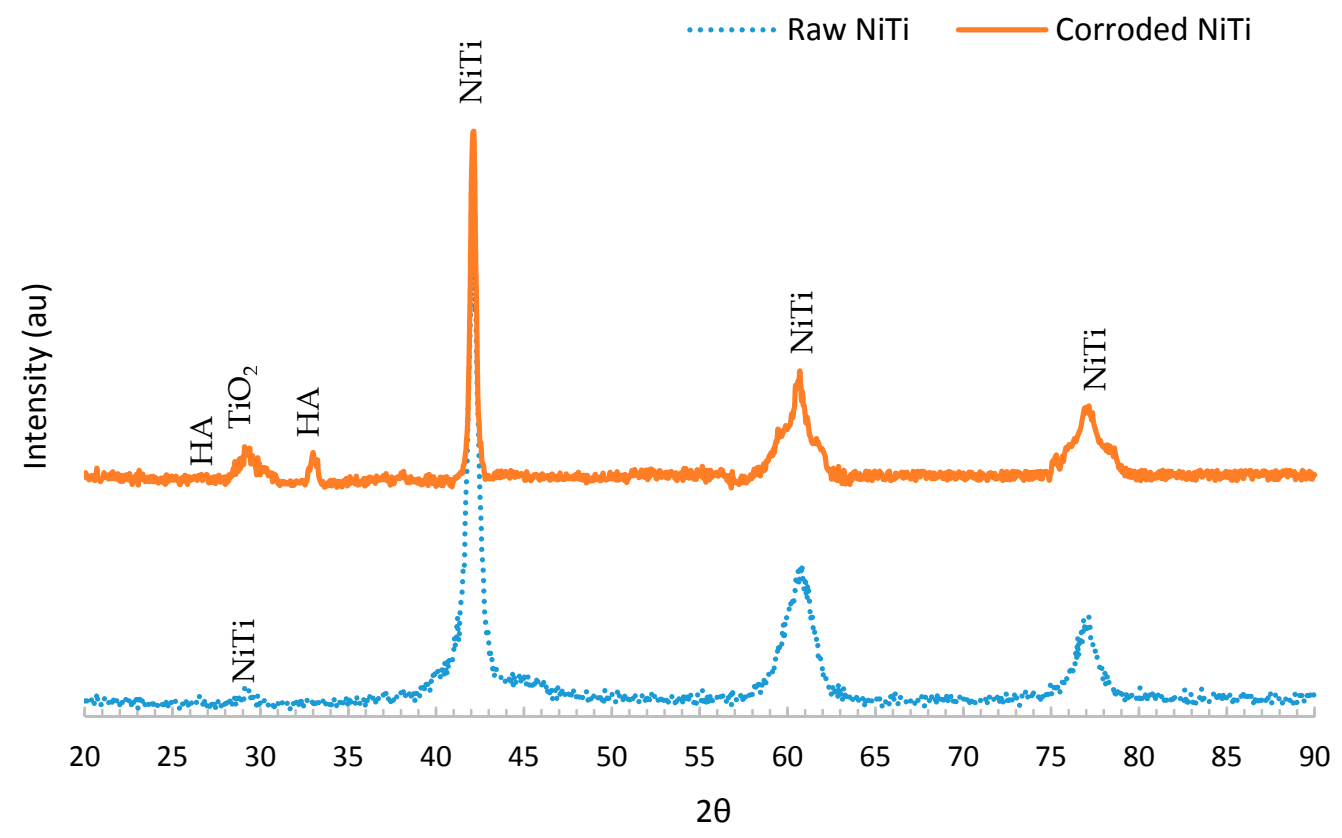

Figure 8. XRD graphs of additively manufactured (raw) and corroded NiTi parts.

\subsection{Ni Ion Release (Immersion Test)}

The results of the Ni ion release in particles per billion ( $\mathrm{ppb}$ ) after the immersion test can be seen in Figure 9. The results confirm that the amount of the Ni ion released of the AM NiTi (dense structure) was similar to that for the conventionally fabricated NiTi. In addition, the AM porous structures $(15,25,35$ and $50 \%$ porosity) showed higher amounts of $\mathrm{Ni}$ ion release, which confirms the electrochemical corrosion results. For example, introducing $25 \%$ porosity increased the surface area from $594 \mathrm{~mm}^{2}$ for bulk samples to $1997.5 \mathrm{~mm}^{2}$ for the porous sample. Such increase in the surface area exposed to the SBF solution led to an increase in the amount of $\mathrm{Ni}$ ion release from $64 \mathrm{ppb}$ for bulk samples to $176.35 \mathrm{ppb}$ for the $25 \%$ porous structure. However, the maximum Ni ion release of $196.8 \mathrm{ppb}$ in the case of the $50 \%$ porous NiTi structure was still within the range of most of the values for conventionally fabricated NiTi alloys reported in the literature [22,35,36]. For instance, Bernard et al. [22] reported a maximum of $268 \pm 11 \mathrm{ppb}$ of $\mathrm{Ni}$ ion release for conventionally fabricated NiTi samples. This indicates that both the bulk and porous NiTi structures produced using additive manufacturing had $\mathrm{Ni}$ ion release levels similar to those for conventionally fabricated NiTi alloys confirmed to be biocompatible. The surface area calculations and the $\mathrm{Ni}$ ion release results are listed in Table 3.

Table 3. The surface area and Ni ion release measurements for the conventionally fabricated and additively manufactured NiTi samples (bulk and porous).

\begin{tabular}{|c|c|c|c|}
\hline Sample Type & Surface Area $\left(\mathrm{mm}^{2}\right)$ & Ni Ions (ppb) (Diluted) & Ni Ions (ppb) \\
\hline Conventionally-fabricated & 590 & 5.945 & 59.45 \\
\hline $\mathrm{AM}$ (dense) & 594 & 6.4 & 64 \\
\hline AM ( $15 \%$ porosity $)$ & 1620.3 & 12.79 & 127.94 \\
\hline AM ( $25 \%$ porosity) & 1997.5 & 17.64 & 176.35 \\
\hline AM ( $35 \%$ porosity) & 2106.6 & 19.43 & 194.3 \\
\hline AM ( $50 \%$ porosity) & 2116.3 & 19.68 & 196.8 \\
\hline
\end{tabular}




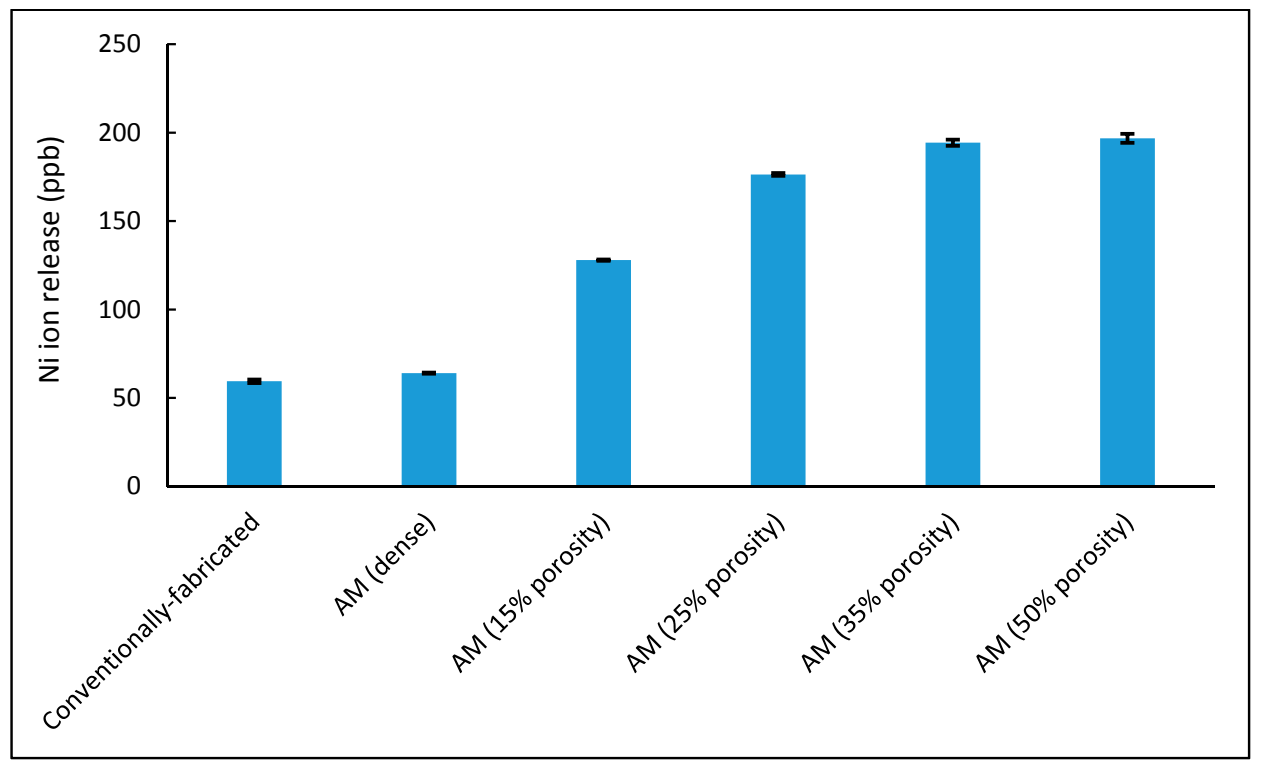

Figure 9. The Ni ion release of two different structures (dense and porous) of additively manufactured NiTi alloys in comparison to the conventionally fabricated NiTi alloy.

\section{Conclusions}

The additively manufactured NiTi parts were found to have a corrosion behavior (electrochemical corrosion and $\mathrm{Ni}$ ion release) similar to that found for the conventionally fabricated NiTi alloy. This indicates that the proposed additive manufacturing process does not result in a deterioration in the corrosion resistance of NiTi parts. In addition, the SEM and XRD analysis of the corroded NiTi samples showed the formation of biocompatible corrosion products on the surface of the sample, which could be beneficial for bone implant applications. Adding porosity to the additively manufactured NiTi parts increased the exposed surface area, which results in a higher electrochemical corrosion current and hence a higher $\mathrm{Ni}$ ion release compared to the bulk NiTi samples. However, the Ni ion release levels reported in this work for all the fabricated structures remain within the range of most of values for conventionally fabricated NiTi alloys reported in the literature. It is worth mentioning that there have been several efforts to reduce the $\mathrm{Ni}$ ion release of conventionally fabricated NiTi parts in the literature using surface modification and coating techniques. Such techniques could be beneficial to implement for additively manufactured NiTi structures to further increase the corrosion resistance and reduce the $\mathrm{Ni}$ ion release rates.

Acknowledgments: The authors wish to acknowledge partial support for this research from Third Frontier (State of Ohio) grant 15-791, titled "Additive Manufacture of Stiffness-Matched Skeletal Fixation Hardware".

Author Contributions: Hamdy Ibrahim and Mohammad Elahinia conceived and designed the experiments; AhmadReza Jahadakbar, Amir Dehghan, Narges Shayesteh Moghaddam, Amirhesam Amerinatanzi and Hamdy Ibrahim performed the experiments; Hamdy Ibrahim and Amir Dehghan analyzed the data; Mohammad Elahinia contributed reagents/materials/analysis tools; Hamdy Ibrahim, Amir Dehghan, AhmadReza Jahadakbar and Mohammad Elahinia wrote the paper.

Conflicts of Interest: The authors declare no conflict of interest.

\section{References}

1. Esenwein, S.; Bogdanski, D.; Köller, M.; Krone, L.; Epple, M.; Muhr, G. Clinical applications of shape memory alloys based on niti as implant materials-Possibilities in trauma and orthopaedic surgery. SMST Proc. 2006. [CrossRef]

2. Duerig, T.; Pelton, A.; Stöckel, D. An overview of nitinol medical applications. Mater. Sci. Eng. A 1999, 273, 149-160. [CrossRef] 
3. Peitsch, T.; Klocke, A.; Kahl-Nieke, B.; Prymak, O.; Epple, M. The release of nickel from orthodontic niti wires is increased by dynamic mechanical loading but not constrained by surface nitridation. J. Biomed. Mater. Res. Part A 2007, 82, 731-739. [CrossRef] [PubMed]

4. Lima de Miranda, R.; Zamponi, C.; Quandt, E. Micropatterned freestanding superelastic tini films. Adv. Eng. Mater. 2013, 15, 66-69. [CrossRef]

5. Elahinia, M.H.; Hashemi, M.; Tabesh, M.; Bhaduri, S.B. Manufacturing and processing of niti implants: A review. Prog. Mater. Sci. 2012, 57, 911-946. [CrossRef]

6. Shabalovskaya, S.A. On the nature of the biocompatibility and on medical applications of niti shape memory and superelastic alloys. Bio-Med. Mater. Eng. 1996, 6, 267-289.

7. Rahmanian, R.; Moghaddam, N.S.; Haberland, C.; Dean, D.; Miller, M.; Elahinia, M. Load bearing and stiffness tailored niti implants produced by additive manufacturing: A simulation study. In SPIE Smart Structures and Materials + Nondestructive Evaluation and Health Monitoring: International Society for Optics and Photonics; SPIE: Bellingham, WA, USA, 2014; pp. 905814-905818.

8. Stergioudi, F.; Vogiatzis, C.; Pavlidou, E.; Skolianos, S.; Michailidis, N. Corrosion resistance of porous niti biomedical alloy in simulated body fluids. Smart Mater. Struct. 2016, 25, 095024. [CrossRef]

9. Hu, T.; Chu, C.; Xin, Y.; Wu, S.; Yeung, K.W.; Chu, P.K. Corrosion products and mechanism on niti shape memory alloy in physiological environment. J. Mater. Res. 2010, 25, 350-358. [CrossRef]

10. Hu, T.; Xin, Y.; Wu, S.; Chu, C.; Lu, J.; Guan, L.; Chen, H.; Hung, T.F.; Yeung, K.; Chu, P.K. Corrosion behavior on orthopedic niti alloy with nanocrystalline/amorphous surface. Mater. Chem. Phys. 2011, 126, 102-107. [CrossRef]

11. Figueira, N.; Silva, T.; Carmezim, M.; Fernandes, J. Corrosion behaviour of niti alloy. Electrochim. Acta 2009, 54, 921-926. [CrossRef]

12. Tan, L.; Dodd, R.; Crone, W. Corrosion and wear-corrosion behavior of niti modified by plasma source ion implantation. Biomaterials 2003, 24, 3931-3939. [CrossRef]

13. Xu, J.; Jin, X.; Luo, J.; Zhong, Z. Fabrication and properties of porous niti alloys by microwave sintering for biomedical applications. Mater. Lett. 2014, 124, 110-112. [CrossRef]

14. Cheng, F.; Shi, P.; Man, H. A preliminary study of $\mathrm{TiO}_{2}$ deposition on niti by a hydrothermal method. Surf. Coat. Technol. 2004, 187, 26-32. [CrossRef]

15. Rongo, R.; Ametrano, G.; Gloria, A.; Spagnuolo, G.; Galeotti, A.; Paduano, S.; Valletta, R.; D'Antò, V. Effects of intraoral aging on surface properties of coated nickel-titanium archwires. Angle Orthod. 2013, 84, 665-672. [CrossRef] [PubMed]

16. Wever, D.; Veldhuizen, A.; De Vries, J.; Busscher, H.; Uges, D.; Van Horn, J. Electrochemical and surface characterization of a nickel-titanium alloy. Biomaterials 1998, 19, 761-769. [CrossRef]

17. Ma, C.; Andani, M.T.; Qin, H.; Moghaddam, N.S.; Ibrahim, H.; Jahadakbar, A.; Amerinatanzi, A.; Ren, Z.; Zhang, H.; Doll, G.L. Improving surface finish and wear resistance of additive manufactured nickel-titanium by ultrasonic nano-crystal surface modification. J. Mater. Process. Technol. 2017, 249, 433-440. [CrossRef]

18. Wu, H.; Wang, T.; Liu, X.; Lin, N.; Liu, X.; He, Z.; Wang, Z. Fabrication and corrosion resistance of the ti-rich alloyed layer on the surface of niti alloys. Int. J. Electrochem. Sci. 2017, 12, 2376-2388. [CrossRef]

19. Bolat, G.; Mareci, D.; Iacoban, S.; Cimpoesu, N.; Munteanu, C. The estimation of corrosion behavior of niti and nitinb alloys using dynamic electrochemical impedance spectroscopy. J. Spectrosc. 2012, 2013, 714920. [CrossRef]

20. Ryhänen, J.; Niemi, E.; Serlo, W.; Niemelä, E.; Sandvik, P.; Pernu, H.; Salo, T. Biocompatibility of nickel-titanium shape memory metal and its corrosion behavior in human cell cultures. J. Biomed. Mater. Res. Part A 1997, 35, 451-457. [CrossRef]

21. El Medawar, L.; Rocher, P.; Hornez, J.-C.; Traisnel, M.; Breme, J.; Hildebrand, H. Electrochemical and cytocompatibility assessment of nitinol memory shape alloy for orthodontic use. Biomol. Eng. 2002, 19, 153-160. [CrossRef]

22. Bernard, S.A.; Balla, V.K.; Davies, N.M.; Bose, S.; Bandyopadhyay, A. Bone cell-materials interactions and ni ion release of anodized equiatomic niti alloy. Acta Biomater. 2011, 7, 1902-1912. [CrossRef] [PubMed]

23. Andani, M.T.; Moghaddam, N.S.; Haberland, C.; Dean, D.; Miller, M.J.; Elahinia, M. Metals for bone implants. Part 1. Powder metallurgy and implant rendering. Acta Biomater. 2014, 10, 4058-4070. [CrossRef] [PubMed] 
24. Wang, X.; Xu, S.; Zhou, S.; Xu, W.; Leary, M.; Choong, P.; Qian, M.; Brandt, M.; Xie, Y.M. Topological design and additive manufacturing of porous metals for bone scaffolds and orthopaedic implants: A review. Biomaterials 2016, 83, 127-141. [CrossRef] [PubMed]

25. Ibrahim, H.; Esfahani, S.N.; Poorganji, B.; Dean, D.; Elahinia, M. Resorbable bone fixation alloys, forming, and post-fabrication treatments. Mater. Sci. Eng. C 2017, 70, 870-888. [CrossRef] [PubMed]

26. Amerinatanzi, A.; Moghaddam, N.S.; Ibrahim, H.; Elahinia, M. The effect of porosity type on the mechanical performance of porous niti bone implants. In Proceedings of the ASME 2016 Conference on Smart Materials, Adaptive Structures and Intelligent Systems, San Antonio, TX, USA, 10-12 September 2016; American Society of Mechanical Engineers: New York, NY, USA, 2016; p. V002T006A018.

27. Jahadakbar, A.; Shayesteh Moghaddam, N.; Amerinatanzi, A.; Dean, D.; Karaca, H.E.; Elahinia, M. Finite element simulation and additive manufacturing of stiffness-matched niti fixation hardware for mandibular reconstruction surgery. Bioengineering 2016, 3, 36. [CrossRef] [PubMed]

28. Moghaddam, N.S.; Skoracki, R.; Miller, M.; Elahinia, M.; Dean, D. Three dimensional printing of stiffness-tuned, nitinol skeletal fixation hardware with an example of mandibular segmental defect repair. Procedia CIRP 2016, 49, 45-50. [CrossRef]

29. Youssef, A.; Hollister, S.J.; Dalton, P.D. Additive manufacturing of polymer melts for implantable medical devices and scaffolds. Biofabrication 2017, 9, 012002. [CrossRef] [PubMed]

30. Ibrahim, H.; Mehanny, S.; Darwish, L.; Farag, M. A comparative study on the mechanical and biodegradation characteristics of starch-based composites reinforced with different lignocellulosic fibers. J. Polym. Environ. 2017, 1-14. [CrossRef]

31. Ibrahim, H.; Klarner, A.D.; Poorganji, B.; Dean, D.; Luo, A.A.; Elahinia, M. Microstructural, mechanical and corrosion characteristics of heat-treated Mg-1.2 Zn-0.5 ca (wt \%) alloy for use as resorbable bone fixation material. J. Mech. Behav. Biomed. Mater. 2017, 69, 203-212. [CrossRef] [PubMed]

32. Martorelli, M.; Maietta, S.; Gloria, A.; De Santis, R.; Pei, E.; Lanzotti, A. Design and analysis of 3d customized models of a human mandible. Procedia CIRP 2016, 49, 199-202. [CrossRef]

33. Oyane, A.; Kim, H.M.; Furuya, T.; Kokubo, T.; Miyazaki, T.; Nakamura, T. Preparation and assessment of revised simulated body fluids. J. Biomed. Mater. Res. Part A 2003, 65, 188-195. [CrossRef] [PubMed]

34. Hansen, A.W.; Führ, L.T.; Antonini, L.M.; Villarinho, D.J.; Marino, C.E.B.; Malfatti, C.D.F. The electrochemical behavior of the niti alloy in different simulated body fluids. Mater. Res. 2015, 18, 184-190. [CrossRef]

35. Ramazanzadeh, B.A.; Ahrari, F.; Sabzevari, B.; Habibi, S. Nickel ion release from three types of nickel-titanium-based orthodontic archwires in the as-received state and after oral simulation. J. Dent. Res. Dent. Clin. Dent. Prospect. 2014, 8, 71.

36. Azizi, A.; Jamilian, A.; Nucci, F.; Kamali, Z.; Hosseinikhoo, N.; Perillo, L. Release of metal ions from round and rectangular niti wires. Prog. Orthod. 2016, 17, 10. [CrossRef] [PubMed] 